\title{
Grass cultivar diversity and endophyte infection affect abundance of herbivores and their natural enemies
}

\author{
C.B. MÜLLER, S.A. HÄRRI, V. BOREUX and J. KRAUSS \\ Institute of Environmental Sciences, University of Zürich, Winterthurerstrasse 190, CH-8057 Zürich
}

cbm@uwinst.unizh.ch

\begin{abstract}
How does diversity in plant cultivars and endophyte infection affect higher trophic levels? We manipulated the number of cultivars ( 1 or 4$)$ and the endophyte infection (-E, $+\mathrm{E}$, and both, $-\mathrm{E}$ and $+\mathrm{E})$ of potted Lolium perenne plants and left aphids and their parasitoids to assemble naturally. Aphid number and plant biomass were not influenced by our treatments, while the number of parasitised aphids (mummies) was significantly higher on mixed plant stands than on monocultures. The effect of endophytes was stronger in mixed plant stands than in monocultures with the most mummies found in endophyte-free mixed plant stands. Although number of mummies did not differ among cultivars, the rate of parasitism varied with cultivar and showed an endophyte $\mathrm{x}$ cultivar interaction. The number of successfully emerging parasitoids was also higher on high diversity treatments than on monocultures, indicating that increased diversity at resource levels translates to increased abundance at consumer levels.

Key words: fungal endosymbionts, biodiversity, genetic diversity, multitrophic interactions, insect food webs, insect density, Neotyphodium lolii
\end{abstract}

\section{Introduction}

Empirical biodiversity studies and theoretical models show that plant species diversity has positive effects on the productivity of a system and on the diversity of consumer communities because herbivores show specialisation and higher herbivore abundance can be supported by highly productive, more diverse plant systems (Loreau et al. 2002). As a consequence, more predator species should be supported by such diverse systems (Hunter \& Price 1992). Some recent studies show that diversity of plant genotypes can cause similar cascading effects (Zuh et al. 2000; Crutsinger et al. 2006). In addition to plant genotype diversity, the associations of plants with endosymbionts create a second level of diversity because the associations between plants and fungi are genotypically unique (Schardl \& Moon 2003). However, the associations with fungal endophytes could have opposing effects to plant genotypic diversity because endophyte infection protects the plants against herbivore feeding through toxins (Clay \& Schardl 2002), thus restricting the energy that flows up the food chain. Therefore, asexual endophytes that are commonly found in grasses can have negative effects on herbivore abundance as well as on the abundance of their natural enemies (Omacini et al. 2001; Müller \& Krauss 2005) and they can alter the relationship between plant species diversity and ecosystem function (Rudgers et al. 2004).

Here we ask whether cultivar diversity and endophyte infection diversity in the English ryegrass, Lolium perenne, can affect aphid herbivore abundance and the abundance of associated parasitoids. We hypothesised that over a gradient of plant genotypic diversity the abundance of associated consumers should increase while the presence of endophytes must counteract such a pattern somehow. However, in the highest diversity levels where plant genotypes and endophyte genotypes are maximised there should generally be positive effects on insect abundance.

\section{Material and Methods}

On May 112005 we seeded a total of 165 pots $(\varnothing 25 \mathrm{~cm})$ with different diversity levels of Lolium perenne with \pm 200 seeds $(0.3 \mathrm{~g})$ and kept the germinating plants in the greenhouse until end of May. The cultivars were provided by Brian Tapper, AgResearch, NZ and consisted of Imp (Lolium x boucheanum, Grassland Impact), Nui (L. perenne Grassland Nui), Pac ( $L$. perenne Grassland Pacific) and Sam (L. perenne, Grassland Samson) with each cultivar either infected or uninfected with the endophyte Neotyphodium lolii as confirmed by diagnostic staining (Saha et al. 1988). The four cultivars and two infection levels were each replicated 15 times in monocultures (120 pots; genotype diversity $=1$ ). Fifteen pots consisted of all four uninfected cultivars and 15 pots all four infected cultivars mixed together ( 30 pots; genotype diversity $=4$; mixtures). A last set of 15 pots contained all four cultivars and the two infection levels mixed together (15 pots; genotype diversity $=8$; mixtures). All pots were moved to an experimental garden on May 31 where they were randomly placed within three blocks with 55 pots in each. Pots were watered regularly as required.

We collected mummies (parasitised aphids) from the pots at three sampling dates, between July 19-21, July 27-29 and August 4-8. At the last sampling dates, total number of aphids per pot was counted and the above ground tissue of the plants was cut at soil level to determine biomass produced per pot. The plant material was oven dried for 3 days at $60^{\circ} \mathrm{C}$ and the dry biomass was measured for each pot.

We analysed the data with a hierarchical model to test for the influential effects on several dependent variables. The dependent variables analysed were: Number of aphids $(\ln [\mathrm{x}+1]$ - transformed) at the last sampling date, number of mummies summed over all sampling dates, rate of parasitism and number of emerged parasitoids $(\ln [\mathrm{x}+1]$ - transformed $)$ and plant biomass. For the hierarchical model, we used the function Im and the different factors were entered sequentially into the model according to their hierarchy. The hierarchical sequence was block, genetic diversity (difference between monocultures and mixtures), genetic diversity2 (within mixture diversity), endophyte presence and the interaction between endophytes and genetic diversity, and finally, within genetic diversities of one the effects of the different cultivars and their interaction with endophytes (Fig. 1). All figures show averages and standard errors across the three diversity levels and contrast between infected and uninfected plants.

\section{Results}

Considerable variation existed across the genetic diversity treatments for all response variables: plant biomass, number of aphids, number of parasitoids emerged and rate of parasitism (Fig. 2). We assessed aphids at the end of the experiment when aphid numbers were very low which may be the reason that no significant effects of any treatment on aphid densities were found (Table 1; Fig. 2a). The dominant aphid species we observed was Rhopalosiphum padi, while Metopolophium festucae occurred in 
Table 1 The effects of genotypic plant diversity and endophyte infection on plant and insect performance. 'Diversity' refers to the contrast between monoculture and higher levels of genetic diversity and 'Diversity2' refers to the contrast between diversity levels 4 and 8 (see Figure 1). ${ }^{\star \star *} \mathrm{P}<0.001,{ }^{\star \star} \mathrm{P}<0.01,{ }^{*} \mathrm{P}<0.05$.

\begin{tabular}{lccccc}
\hline Plant biomass & \multicolumn{1}{c}{} \\
\hline & df & SS & MS & F value & P value \\
\hline Block & 2 & 2204.1 & 1102.0 & 11.41 & $<0.0001$ *** \\
Diversity & 1 & 12.2 & 12.2 & 0.13 & 0.723 \\
Diversity2 & 1 & 33.9 & 33.9 & 0.35 & 0.554 \\
Endophyte & 1 & 24.5 & 24.5 & 0.25 & 0.615 \\
Diversity x Endophyte & 1 & 20.9 & 20.9 & 0.22 & 0.642 \\
Cultivar & 3 & 736.4 & 245.5 & 2.54 & 0.058 \\
Endophyte x Cultivar & 3 & 62.4 & 20.8 & 0.22 & 0.887 \\
Residuals & 152 & 14675.7 & 96.6 & & \\
\hline
\end{tabular}

\section{Number of aphids [In $(x+1)$ - transformed]}

\begin{tabular}{lccccc}
\hline & df & SS & MS & F value & $p$ value \\
\hline Block & 2 & 6.956 & 3.478 & 4.70 & $0.010^{*}$ \\
Diversity & 1 & 0.128 & 0.128 & 0.17 & 0.678 \\
Diversity2 & 1 & 0.056 & 0.056 & 0.08 & 0.784 \\
Endophyte & 1 & 0.027 & 0.027 & 0.04 & 0.849 \\
Diversity x Endophyte & 1 & 0.169 & 0.169 & 0.23 & 0.634 \\
Cultivar & 3 & 2.830 & 0.943 & 1.27 & 0.285 \\
Endophyte x Cultivar & 3 & 3.371 & 1.124 & 1.52 & 0.212 \\
Residuals & 152 & 112.571 & 0.741 & & \\
\hline
\end{tabular}

\section{Number of mummies}

\begin{tabular}{lccccc}
\hline & df & SS & MS & F value & $\mathrm{p}$ value \\
\hline Block & 2 & 8057 & 4029 & 16.90 & $<0.0001^{* * *}$ \\
Diversity & 1 & 2318 & 2318 & 9.73 & $0.002^{* *}$ \\
Diversity2 & 1 & 109 & 109 & 0.46 & 0.500 \\
Endophyte & 1 & 1227 & 1227 & 5.15 & $0.025^{*}$ \\
Diversity x Endophyte & 1 & 1368 & 1368 & 5.74 & $0.018^{*}$ \\
Cultivar & 3 & 274 & 91 & 0.38 & 0.765 \\
Endophyte x Cultivar & 3 & 547 & 182 & 0.77 & 0.515 \\
Residuals & 152 & 36233 & 238 & & \\
\hline
\end{tabular}

Number of emerged parasitoids [ $\ln (x+1)$ - transformed]

\begin{tabular}{|c|c|c|c|c|c|}
\hline & df & SS & MS & F value & $p$ value \\
\hline Block & 2 & 6.897 & 3.449 & 14.48 & $<0.0001^{\star \star \star}$ \\
\hline Diversity & 1 & 2.792 & 2.792 & 11.72 & $0.0008^{* * *}$ \\
\hline Diversity2 & 1 & 0.306 & 0.306 & 1.28 & 0.259 \\
\hline Endophyte & 1 & 0.416 & 0.416 & 1.75 & 0.188 \\
\hline Diversity $x$ Endophyte & 1 & 0.014 & 0.014 & 0.06 & 0.806 \\
\hline Cultivar & 3 & 0.443 & 0.148 & 0.62 & 0.603 \\
\hline Endophyte $\times$ Cultivar & 3 & 0.621 & 0.207 & 0.87 & 0.458 \\
\hline Residuals & 152 & 36.201 & 0.238 & & \\
\hline \multicolumn{6}{|l|}{ Rate of Parasitism } \\
\hline & $\mathrm{df}$ & SS & MS & $F$ value & $\mathrm{p}$ value \\
\hline Block & 2 & 0.38760 & 0.19380 & 13.40 & $<0.0001^{* \star \star}$ \\
\hline Diversity & 1 & 0.00751 & 0.00751 & 0.52 & 0.472 \\
\hline Diversity2 & 1 & 0.00290 & 0.00290 & 0.20 & 0.655 \\
\hline Endophyte & 1 & 0.00001 & 0.00001 & 0.001 & 0.980 \\
\hline Diversity $x$ Endophyte & 1 & 0.04595 & 0.04595 & 3.18 & 0.077 \\
\hline Cultivar & 3 & 0.11750 & 0.03917 & 2.71 & $0.047^{*}$ \\
\hline Endophyte $\times$ Cultivar & 3 & 0.11610 & 0.03870 & 2.68 & 0.049 * \\
\hline Residuals & 152 & 2.19779 & 0.01446 & & \\
\hline
\end{tabular}


Figure 1 Hierarchical statistical design of our analyses that test for effects by plant genetic composition and endophyte infection on measured response variables of plant biomass, aphid density, mummy density, rate of parasitism and emergence rate of parasitoids.

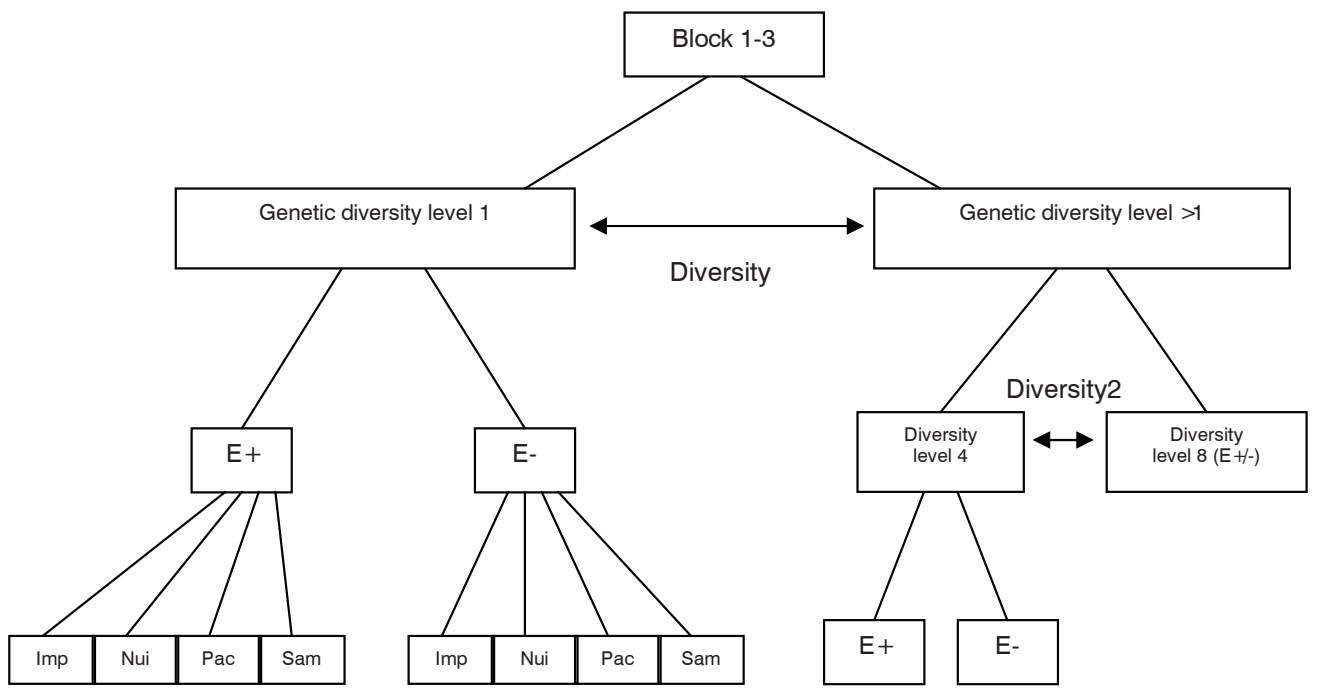

very low numbers. Across all treatments and the three sampling dates, we recorded 6085 mummies, of which 895 successfully emerged in the laboratory. The high number of mummies indicates that our plants were initially colonised by very high aphid numbers. The analysis contrasting one or more genetic diversity levels showed a significant influence on the total mummies collected, with more mummies on pots with higher levels of genetic diversity (Table 1). Endophyte infection and the interaction between genetic diversity and endophytes had a significant effect as well, showing that the absence of endophyte infection increased the number of total mummies collected only on pots with a genetic diversity of four (Table 1, Fig. 2b). The number of emerged parasitoids was higher on pots with higher levels of genetic diversity compared to pots with monocultures but endophyte presence had no significant effect (Table 1; Fig. $2 \mathrm{c}$ ). The rate of parasitism (expressed as mummies divided by mummies and aphids) was high overall (range between $77 \%$ and $93 \%$ ) because of the low aphid number and showed a significant cultivar $\mathrm{x}$ endophyte interaction with the grass cultivar Sam without endophyte having the lowest rate of parasitism of 77 percent (Table 1). The proportion of parasitoids that were attacked by secondary parasitoids was extremely high across all treatments with values ranging between 84 and $87 \%$. In our experiment, the plant biomass was neither changed by genetic diversity, nor by the presence of endophytes, indicating no strong cascading effects on plant productivity (Table 1; Fig. 2d).

\section{Discussion}

We show that densities within higher trophic consumer levels, i.e. parasitoids, are enhanced by the genotypic diversity of the basal plant resource and are also affected by the endophyte infection in the plants. Effects of genotype diversity on trophic cascades have been shown in case studies before (Zuh et al. 2000; Crustinger et al. 2006). Our study, however, shows for the first time that endophytic fungi can interact with such a diversity effect that acts from the basal resource upwards. An increase in genetically diverse plant resources resulted in higher densities of parasitoids and higher rates of parasitism, which ultimately should be beneficial for the plants.
As we could not detect any significant effect on plant biomass, we assume that aphids, which were controlled by parasitoids, did not harm their food plant substantially during our experimental period. A second explanation could be that hyperparasitoids controlled the primary parasitoids, since we detected high rates of hyperparasitism. In such a case, although the aphids would have been released from control by the parasitoids, they still did not affect the plant biomass produced. As we only measured aphid numbers at the end of the experiment, we cannot contrast between the two possibilities.

Endosymbiontic fungal endophytes can affect local plant species composition via competition (Clay \& Holah 1999) or herbivore feed-backs (Clay et al. 2005), plant productivity via soil feed-backs (Matthews \& Clay 2001), plant litter decomposition (Lemons et al 2005) and the invasibility of plant communities (Rudgers et al. 2005). Here we show that endophytes can also interact with diversity effects of plants on higher trophic levels and therefore, with the ecosystem function of herbivore control. Thus, effects of micro-organisms on ecosystems are a new field in biodiversity-ecosystem functioning research and should be considered in further studies.

\section{ACKNOWLEDGMENTS}

Thanks go to Dr Brian Tapper for providing the seed material. Susanne Müller, Claudio de Sassi, Gabor van Bethlenfalvy and Manuel Krämer helped in the field. Thanks to Alison Popay and Errol Thom who provided critical comments on the manuscript. Financial support came from SNSF (Grant number 631065950).

\section{REFERENCES}

Clay, K.; Holah, J. 1999. Fungal endophyte symbiosis and plant diversity in successional fields. Science 286: 1742-1744.

Clay, K.; Schardl, C. 2002. Evolutionary origins and ecological consequences of endophyte symbiosis with grasses. The American Naturalist 160: S99-S127.

Clay, K.; Holah, J.; Rudgers, J.A. 2005. Herbivores cause a rapid 
Figure 2 Mean and SE of (a) aphid number, (b) number of mummies, (c) number of emerged parasitoids, and (d) plant biomass across three plant genotypic diversities $(1,4,8)$ and two infection levels $(+E,-E)$. Note that in the highest diversity of eight only mixed stands of infected and uninfected plants were created.
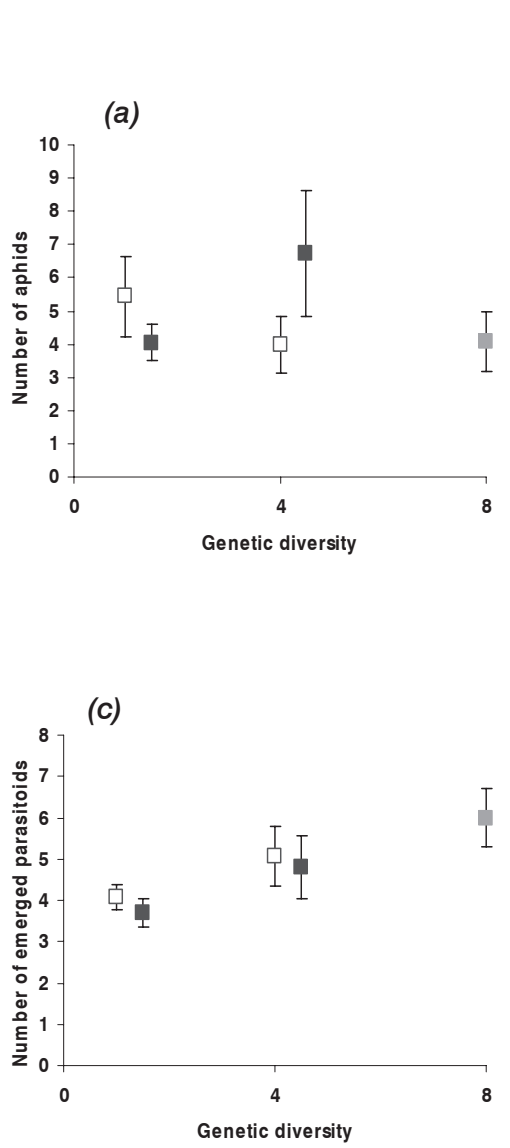

increase in hereditary symbiosis and alter plant community composition. PNAS 102: 12465-12470.

Crutsinger, G.M.; Collins, M.D.; Fordyce, J.A.; Gompert, Z.; Nice, C.C.; Sanders, N.J. 2006. Plant genotypic diversity predicts community structure and governs an ecosystem process. Science 313: 966-968.

Hunter, M.D.; Price, P.W. 1992. Playing chutes and ladder: Heterogeneity and the relative roles of bottom-up and topdown forces in natural communities. Ecology 73: 724-732.

Lemons, A.; Clay, K.; Rudgers, J.A. 2005. Connecting plantmicrobial interactions above and belowground: a fungal endophytes affects decomposition. Oecologia 145: 595-604.

Loreau, M.; Naeem, S.; Inchausti, P. (eds.) 2002. Biodiversity and Ecosystem Functioning: Synthesis and Perspectives. Oxford University Press, Oxford, UK.

Matthews, J.W.; Clay, K. 2001. Influence of fungal endophyte infection on plant-soil feedback and community interactions. Ecology 82: 500-509.

Müller, C.B.; Krauss, J. 2005. Symbiosis between grasses and asexual

E-

$E+/=$ $\square \mathrm{E}-$ E+/+ $+/-$

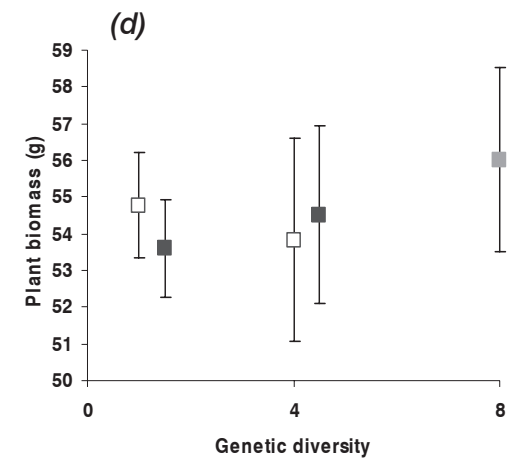

fungal endophytes. Current Opinion in Plant Biology 8: 450-456. Omacini, M.; Chaneton, E.J.; Ghersa, C.M.; Müller, C.B. 2001. Symbiotic fungal endophytes control insect host-parasite interaction webs. Nature 409: 78-81.

Rudgers, J.A.; Koslow, J.M.; Clay, K. 2004. Endophytic fungi alter relationships between diversity and ecosystem properties. Ecology Letters 7:42-51.

Rudgers, J.A.; Mattingly, W.B.; Koslow, J.M. 2005 Mutualistic fungus promotes plant invasion into diverse communities. Oecologia 144: 463-471.

Schardl, C.L.; Moon, C.D. 2003. Processes of species evolution in Epichloë/Neotyphodium endophytes of grasses. In: Clavicipitalean Fungi. Eds. White, J.F.; Bacon, C.W.; HywelJones, N.L.; Spatafora, J.W. Mycology 19: 273-310.

Zuh, Y.; Chen, H.; Fan, J.; Wang, Y.; Li, Y.; Chen, J., Fan, J.; Yang, S.; Hu, L.; Leung, H.; Mew, T.W.; Teng, P.S.; Wang, Z.; Mundt, C.C. 2000. Genetic diversity and disease control in rice. Nature 406: 718-722. 